\title{
The concept of intraoperative, “unsuspected” N2: It's suspect
}

\author{
Ryan A. Macke, MD
}

\author{
From the Department of Surgery, University of Wisconsin School of Medicine and Public Health, Madison, Wis \\ Disclosures: Author has nothing to disclose with regard to commercial support. \\ Received for publication Jan 8, 2016; accepted for publication Jan 8, 2016; available ahead of print Feb 11, 2016. \\ Address for reprints: Ryan A. Macke, MD, H4/318 Clinical Sciences Center, 600 Highland Ave, Madison, WI \\ 53792 (E-mail: macke@surgery.wisc.edu). \\ J Thorac Cardiovasc Surg 2016;151:1389-90 \\ $0022-5223 / \$ 36.00$ \\ Copyright (C) 2016 by The American Association for Thoracic Surgery \\ http://dx.doi.org/10.1016/j.jtcvs.2016.01.012
}

Little controversy appears to exist about the proper course of action when "unsuspected" N2 disease is found at thoracotomy. The decision to proceed with resection is supported by current guidelines, 1,2 and few have argued in favor of the alternative to abort. ${ }^{3}$ However, data supporting resection are limited, primarily based on retrospective series reporting favorable outcomes for $\mathrm{cN} 0-1 / \mathrm{pN} 2$ disease initially treated with surgery. ${ }^{4}$ Some also argue that, once a thoracotomy has been performed, the minimal added morbidity of resection is justified, given the reasonable expected survival in these select patients. ${ }^{1}$ Strictly speaking, N2 metastasis diagnosed prior to resection is $\mathrm{cN} 2$ disease (thoracotomy or not), in which case some may wonder if neoadjuvant or definitive systemic therapy is more appropriate, similar to other "types" of cN2 disease. 1,2

Yang and colleagues ${ }^{5}$ again turn to the National Cancer Database in an attempt to improve the limited evidence guiding management of "unsuspected" N2 disease. Outcomes are reported for 2047 patients who had "unsuspected" N2 non-small cell lung cancer (cT1-3N0-1/pN2) that was treated with primary surgery using lobectomy, during the period from 1998 to 2006 . Overall 5-year survival was $30 \%$, which is comparable to results from previous retrospective series of well-staged "unsuspected" N2 patients treated with primary resection. ${ }^{4}$ In addition, improved survival was demonstrated in patients who received adjuvant treatment including chemotherapy. The authors perform propensity-matched analyses, comparing "unsuspected" $\mathrm{cN} 0-1 / \mathrm{pN} 2$ patients treated with primary resection and "suspected" cN2 patients treated with neoadjuvant therapy and lobectomy to "estimate the effect" of these multimodal strategies. The unmatched comparison demonstrated worse long-term survival for the "unsuspected" group; however, no difference was seen in matched analyses.

Strengths of this article include the large sample size and use of a well-respected national database that captures roughly $70 \%$ of newly diagnosed cancers annually in the United States. This study is the first population-based study that addresses "unsuspected" N2 disease. However, this study suffers from the issue often seen in large-database analyses-lack of clinically relevant details that are needed to address the question at hand.

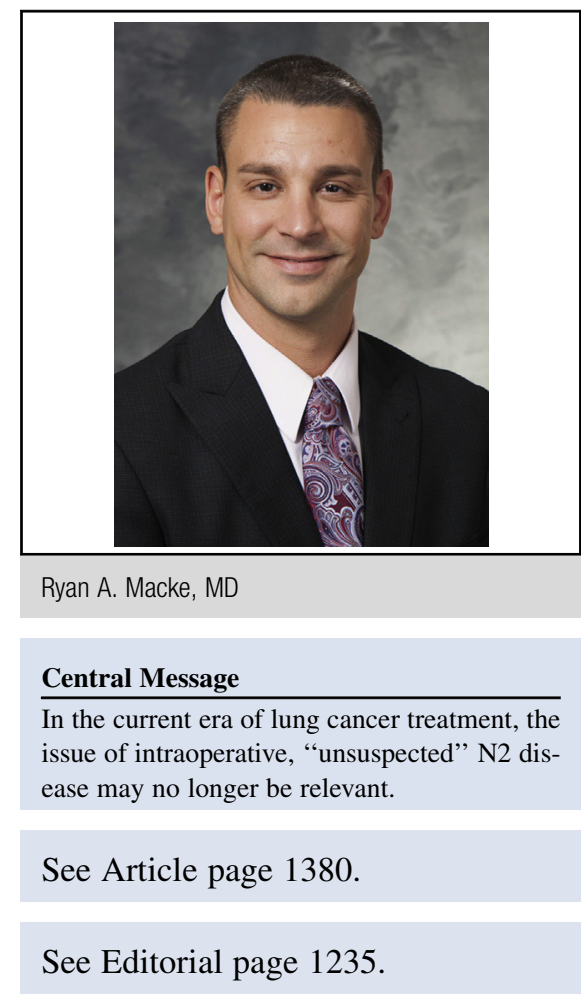

Patients who have true "unsuspected" N2 disease are specifically those who have undergone thorough preoperative mediastinal assessment and are presumed to have minimal N2 tumor burden. ${ }^{1}$ Most well-staged, cN0-1/pN2 patients have single-station, microscopic ("incidental") disease. ${ }^{4}$ Long-term outcomes after primary resection seem better in this subset of "minimal" N2 patients, compared with those who have inadequately staged $\mathrm{pN} 2$ ("ignored" or "underappreciated") and cN2 disease found via biopsy, or suspected on imaging.

Despite thoughtful propensity matching, the "unsuspected" cN0-1/pN2 and "suspected" cN2 groups analyzed in this study are unlikely to be comparable. Details regarding important preoperative variables, such as extent of clinical staging, N2 tumor burden, and functional status are not available in the National Cancer Database. Without these and other clinically relevant details, adequate propensity matching cannot be performed as a means to make a fair assessment of various multimodal strategies for cases of "unsuspected" $\mathrm{N} 2$ disease. The degree of heterogeneity within the "unsuspected" N2 (ie, "incidental," "underappreciated," or "ignored") and "suspected" N2 (single-station, multistation, and "bulky") groups is unknown as well, further weakening the comparison of these groups and limiting ability to identify useful prognostic factors to guide decision making. 
How often are surgeons faced with this proposed clinical scenario after adequate preoperative staging? In this study, the proportion of intraoperative versus postoperative discovery of "unsuspected" $\mathrm{N} 2$ is unknown. The range of $2 \%$ to $18 \%$ reported in the referenced series actually refers to thoroughly staged $\mathrm{cNO}-1$ patients who had "incidental" N2 involvement that was found after resection. ${ }^{5}$ No recent series report the true incidence of intraoperative, pre-resection, "unsuspected" $\mathrm{N} 2$ disease, perhaps because the proposed scenario rarely occurs in clinical practice today. Assuming that most surgeons do not perform routine pre-resection mediastinal lymph node assessment, the most likely reasons for investigating the mediastinum at thoracotomy might be that "suspected" $\mathrm{N} 2$ disease was seen on imaging and could not be proven by other means, or that "ignored" N2 was found because of inadequate preoperative staging. In either case, the favorable outcomes seen in primarily resected "minimal" $\mathrm{N} 2$ patients cannot be expected with primary resection. ${ }^{4}$ The accuracy of preoperative clinical staging has improved immensely with advances in modern imaging and invasive mediastinal staging techniques. In addition, guidelines have become more explicit regarding who should undergo invasive mediastinal staging. ${ }^{6}$ If we are doing our due diligence and appropriately staging patients prior to resection, the chances of getting to thoracotomy to discover "incidental" N2 disease should be slim to none.

In summary, Yang and colleagues ${ }^{5}$ demonstrate that long-term survival can be achieved in a subgroup of patients who likely have "minimal" N2 disease, and rein- force the importance of using adjuvant chemotherapy when postoperative "unsuspected" N2 is discovered. Because clinically relevant details are lacking in this data set, prognostic factors guiding decision making for "unsuspected" N2 disease cannot be identified. However, it may be that the concept of intraoperative "unsuspected" N2 is suspect and this debate is no longer relevant in the current era of lung cancer treatment. Future directions should likely focus on identifying optimal staging protocols that minimize the incidence of postoperative "unsuspected" N2 disease. Prospective studies comparing primary resection and neoadjuvant multimodal therapies for "minimal" N2 disease should also be considered.

\section{References}

1. Ramnath N, Dilling TJ, Harris LJ, Kim AW, Michaud GC, Balekian AA, et al Treatment of stage III non-small cell lung cancer: diagnosis and management of lung cancer, 3rd ed: American College of Chest Physicians evidence-based clinical practice guidelines. Chest. 2013;143(5 Suppl):e314S-340.

2. Ettinger DS, Akerley W, Borghaei H, Chang AC, Cheney RT, Chirieac LR, et al National Comprehensive Cancer Network. Non-small cell lung cancer. J Ntl Compr Canc Netw. 2012;10:1236-71.

3. Ferguson MK. Optimal management when unsuspected N2 nodal disease is identified during thoracotomy for lung cancer: cost-effectiveness analysis. $J$ Thorac Cardiovasc Surg. 2003;126:1935-42.

4. Detterbeck F. What to do with "Surprise" N2?: intraoperative management of patients with non-small cell lung cancer. J Thorac Oncol. 2008;3:289-302.

5. Yang CJ, Kumar A, Gulack BC, Mulvihill M, Hartwig MG, Wang X, et al. Longterm outcomes after lobectomy for non-small cell lung cancer when unsuspected pN2 disease is found: a National Cancer Database analysis. J Thorac Cardiovasc Surg. 2016;151:1380-8.

6. Silvestri GA, Gonzalez AV, Jantz MA, Margolis ML, Gould MK, Tanoue LT, et al. Methods for staging non-small cell lung cancer: diagnosis and management of lung cancer, 3rd ed: American College of Chest Physicians evidence-based clinical practice guidelines. Chest. 2013;143(5 Suppl):e211S-50S. 